\title{
Paediatric and Young Adults Reference Values for Renal, Cardiac and Pancreatic Function Tests for the Population of Taita Taveta County

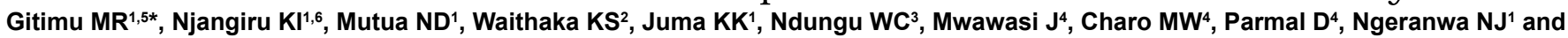 Njagi ENM ${ }^{1}$ \\ ${ }^{1}$ Department of Biochemistry and Biotechnology, Kenyatta University, Nairobi, Kenya \\ ${ }^{2}$ Department of Laboratory Medicine, Kenyatta National Hospital, Nairobi, Kenya \\ ${ }^{3}$ Department of Laboratory Medicine, Thika District Hospital, Nairobi, Kenya \\ ${ }^{4}$ Moi District Hospital, Voi, Nairobi, Kenya \\ ${ }^{5}$ Department of Laboratory Medicine, Jomo Kenyatta University of Agriculture and Technology, Taita Taveta University Campus, Nairobi, Kenya \\ ${ }^{6}$ Department of Chemistry and Biochemistry, Laikipia University, Kenya
}

\begin{abstract}
Reference interval in biochemistry laboratories provides guidelines to the clinicians to interpret the client's results A population of 120 healthy individuals are required in establishing reference ranges to achieve the required and acceptable statistical confidence as per National committee of clinical laboratory standard. To establish the reference ranges for paediatrics and young adults (below 17 years) posse challenges for this category, ethical clearance and need of consent from the guardian for the subject under the study. The main aim of this research was to establish the paediatric reference ranges for renal, cardiac and pancreatic function for young adults in Taita Taveta Population. A prospective study was carried out on $\mathbf{5 7 7}$ healthy young adults and paediatric population from Taita Taveta County, Kenya. Study findings reveal significant variations of renal, cardiac, and pancreatic reference ranges for Taita Taveta, Kenya compared to those supplied by the manufacturers together with the reagent kits in addition to those in literature done in the western world. It is in tandem with findings done in many other studies. This study therefore confirms the need for laboratories to develop their own reference values for their own populations.
\end{abstract}

Keywords: Paediatrics; Young adults; Reference ranges; Reference intervals; Taita Taveta; Pancreatic; Renal and cardiac function

\section{Introduction}

Reference ranges are values for analytes that aid physicians in accurate diagnosis, proper treatment and follow-up of patients. They represent a defined group of individuals. When doing a follow up on patients, a clinician often uses a subject-based reference value to determine the progress made in the management of a pathological disorder [1]. To establish whether a patient has a certain pathological disorder however, group-base reference range is used in the interpretation of laboratory report. Correct interpretation of the results from these analyte presupposes that the clinician and the laboratory medicine physician have good reference information [2]. This group should be as similar as possible to the patients under investigation. The reference population is recruited from the individuals who fulfil a defined inclusion and exclusion criteria as well as a defined partition criterion. The samples from the reference population are then sorted based on the results of inclusion and exclusion criteria. The resulting group of individuals is regarded as a reference population and the results were evaluated statistically to establish the reference values. The upper and lower limit of reference value measurements is dependent on age, sex, genetics, diet, altitude and the methodology used. In addition, reference values produced by reagent manufacturers are determined from analysis of blood samples of a few health workers who do not represent the general population.

Frequently, adult reference intervals are not appropriate for pediatric patients. To assist physicians in treating their pediatric patients in Kenya, paediatric reference values should be used. Currently there are no established population based Kenyan reference limits for paediatric patients. The reference limits in use in Kenya are either borrowed from the textbooks and articles or insert literature from the kit manufacturers [1]. It is therefore recommended that each clinical chemistry laboratory establish its own paediatric reference range for biochemical parameters. The objective for this study was to determine reference ranges for some biochemical parameters for paediatric population from Taita Taveta County, Kenya [3].

\section{Materials and Methods}

\section{Area of study}

This was done at Moi District Hospital, Voi; Taita Taveta County, Kenya. Voi is situated in a sisal farming area in the Coastal region of Kenya.

\section{Participants}

The study group consisted of normal and healthy infants and children aged between 1 to 17 years and had stayed in Taita Taveta, County for not less than six months. Infants and children whose parents and/or guardians consented to participate in the study. The criterion for selection was based on the inclusion criteria.

\section{Ethical consideration}

Kenyatta University Ethical Review Committee (KUERC) and Ministry of Health, Wundanyi District, Kenya; granted the permission to carry out the study.

*Corresponding author: Richard Maina Gitimu, Department of Laboratory Medicine Jomo Kenyatta University of Agriculture and Technology, Taita Taveta University Campus, Nairobi, Kenya, Tel: 020-8150257; E-mail: richardmainag@gmail.com

Received: May 16, 2016; Accepted: September 28, 2016; Published Septembe 30, 2016

Citation: Gitimu MR, Njangiru KI, Mutua ND, Waithaka KS, Juma KK, et al. (2016 Paediatric and Young Adults Reference Values for Renal, Cardiac and Pancreatic Function Tests for the Population of Taita Taveta County. Biochem Anal Biochem 5: 295. doi:10.4172/2161-1009.1000295

Copyright: (c) 2016 Gitimu MR, et al. This is an open-access article distributed under the terms of the Creative Commons Attribution License, which permits unrestricted use, distribution, and reproduction in any medium, provided the original author and source are credited. 
Page 2 of 6

\begin{tabular}{|c|c|c|c|c|c|c|c|c|c|}
\hline \multirow{2}{*}{ Analytes (Unit) } & \multirow{2}{*}{ Sex } & \multirow{2}{*}{$\mathbf{N}$} & \multirow{2}{*}{ Median } & \multicolumn{2}{|c|}{ Percentiles } & \multirow{2}{*}{ Reference value } & \multirow{2}{*}{ RI } & \multicolumn{2}{|c|}{ Difference between M\&F } \\
\hline & & & & 2.5 th & 97.5 th & & & Z-value & Sig \\
\hline \multirow{3}{*}{ BUN (mmol/L) } & M\&F & 551 & 3.81 & 1.9 & 7.6 & $1.9-7.6$ & 5.6 & \multirow{3}{*}{-1.058} & \multirow{3}{*}{0.29} \\
\hline & $\mathrm{F}$ & 270 & 3.76 & 1.9 & 8.2 & $1.9-8.2$ & 6.3 & & \\
\hline & M & 280 & 3.9 & 1.9 & 7.1 & $1.9-7.1$ & 5.2 & & \\
\hline \multirow{3}{*}{ CREAT $(\mu \mathrm{mol} / \mathrm{L})$} & $M \& F$ & 161 & 65 & 45.0 & 91.0 & $45.0-91.0$ & 46 & \multirow{3}{*}{-1.029} & \multirow{3}{*}{0.304} \\
\hline & $\mathrm{F}$ & 61 & 66 & 49.1 & 91.0 & $49.1-91.0$ & 41.9 & & \\
\hline & $M$ & 100 & 65 & 41.0 & 91.0 & $41.0-91.0$ & 50 & & \\
\hline \multirow{3}{*}{$\mathrm{UA}(\mu \mathrm{mol} / \mathrm{L})$} & $M \& F$ & 361 & 205 & 19 & 330 & $19-330$ & 311 & \multirow{3}{*}{-2.64} & \multirow{3}{*}{$0.009^{*}$} \\
\hline & $\mathrm{F}$ & 167 & 198 & 16 & 316 & $16-316$ & 300 & & \\
\hline & $M$ & 193 & 211 & 17 & 340 & $17-340$ & 323 & & \\
\hline \multirow{3}{*}{$\mathrm{PHOS}(\mathrm{mmol} / \mathrm{L})$} & $M \& F$ & 360 & 2 & 1 & 6 & $1-6$ & 5 & \multirow{3}{*}{-1.343} & \multirow{3}{*}{0.179} \\
\hline & $\mathrm{F}$ & 166 & 2 & 1 & 6 & $1-6$ & 5 & & \\
\hline & $M$ & 193 & 2 & 1 & 5 & $1-5$ & 4 & & \\
\hline \multirow{3}{*}{$\mathrm{NA}(\mathrm{mmol} / \mathrm{L})$} & $M \& F$ & 295 & 143 & 129 & 156 & $129-156$ & 27 & \multirow{3}{*}{-2.079} & \multirow{3}{*}{$0.038^{*}$} \\
\hline & $\mathrm{F}$ & 132 & 144 & 127 & 157 & $127-157$ & 30 & & \\
\hline & $M$ & 162 & 142 & 129 & 156 & $129-156$ & 27 & & \\
\hline \multirow{3}{*}{$\mathrm{K}(\mathrm{mmol} / \mathrm{L})$} & $M \& F$ & 483 & 4 & 3 & 9 & $3-9$ & 6 & \multirow{3}{*}{-0.08} & \multirow{3}{*}{0.94} \\
\hline & & 233 & 5 & 3 & 9 & 3-9 & 6 & & \\
\hline & & 249 & 4 & 3 & 9 & $3-9$ & 6 & & \\
\hline \multirow{3}{*}{$\mathrm{CL}(\mathrm{mmol} / \mathrm{L})$} & $M \& F$ & 295 & 105 & 92 & 115 & $92-115$ & 23 & \multirow{3}{*}{-0.498} & \\
\hline & $\mathrm{F}$ & 132 & 105 & 92 & 114 & $92-114$ & 22 & & 0.619 \\
\hline & M & 162 & 105 & 92 & 116 & $92-116$ & 24 & & \\
\hline & $M \& F$ & 492 & 2 & 2 & 3 & $2-3$ & 1 & & \\
\hline $\mathrm{CA}(\mathrm{mmol} / \mathrm{L})$ & $\mathrm{F}$ & 236 & 2 & 2 & 3 & $2-3$ & 1 & -0.617 & 0.537 \\
\hline & $M$ & 255 & 2 & 2 & 3 & $2-3$ & 1 & & \\
\hline & $M \& F$ & 360 & 151 & 52 & 386 & $52-386$ & 334 & & \\
\hline CK (U/L) & $\mathrm{F}$ & 166 & 144 & 52 & 348 & $52-348$ & 296 & -2.945 & $0.003^{*}$ \\
\hline & $M$ & 193 & 162 & 49 & 428 & $49-428$ & 379 & & \\
\hline & $M \& F$ & 553 & 92 & 41 & 184 & $41-184$ & 143 & & \\
\hline AMYL (U/L) & $\mathrm{F}$ & 270 & 95 & 48 & 188 & $48-188$ & 140 & -1.198 & 0.231 \\
\hline & $M$ & 282 & 91 & 38 & 184 & $38-184$ & 146 & & \\
\hline
\end{tabular}

Results are expressed as medians for the number of subjects indicated under the column labelled $\mathrm{N}$. The sex difference is significant at $\mathrm{p} \leq 0.05$, Sig $=$ significance.

Table 1: Establishment of reference ranges for BUN, CREAT, UA, PHOS, NA, K, CL, CA, CK and AMYL for infants and children of Taita Taveta County, Kenya.

\section{Inclusion and exclusion criteria}

Samples for inclusion in the study were to be from normal males and females aged between 1 and 17 years, who were residing in Taita Taveta County; Kenya, and had stayed for more than six months. The exclusion criteria were subjected to all samples that were positive for Syphilis, HIV antibody and Hepatitis B antigen. In addition, all samples collected from pregnant adolescent females were excluded. Finally, adolescents whose parents had not consented to participating in this study.

Immuno-chromatographic reagent strip (Determine HIV-1/2, Tokyo, Japan) was used for screening of HIV 1 and $2.50 \mu \mathrm{L}$ of the sample was applied to the sample pad. After 1 minute chase buffer was applied to the sample pad and the test results read within 15 minutes. Positive results were indicated by the appearance of two red bars each on the control window and on the patient window. Negative results were indicated by the appearance of only one red bar at the control window.

The HbsAg one step Test Strip (HBsAg, Beijing, China) was used for the screening of HbsAg. This was a qualitative lateral flow immunoassay test. The test strip was immersed in a tube containing the serum for screening for 10 to 15 minutes. It was then removed and placed on a non-absorbent flat surface and the results read within 15 minutes. Positive result was indicated by the appearance of two distinct red bars, one on the control region and the other on the test region.
Negative results were indicated by the appearance of only one red bar at the control window.

The syphilis ultra-rapid test which is a qualitative membrane strip based immunoassay (Treponema pallidum Strip, Beijing, China) was used for the screening of Treponema pallidum which is the causative agent of the venereal disease, syphilis. $50 \mu \mathrm{L}$ of the serum sample was placed on the sample pad followed by 1 drop of buffer. The result was read after 10 minutes. Positive result was indicated by the appearance of two red lines, one on the control region and the other on the test region. Negative result was indicated by the appearance of one red line on the control region.

\section{Specimen collection}

Samples from healthy infants and children were collected between the months of July and November 2012. Five millilitres of blood was drawn with the aid of a syringe and needle for children above five years and a scarp vein and syringe for children below five years. This was then transferred to plain vacutainer tubes, labelled with the subject's name and study number. The blood samples were placed in ice-cool box ready for transportation to the laboratory for analysis. In the laboratory, the blood samples were subjected to both inclusion and exclusion criteria.

\section{Specimen transportation, processing and storage}

Specimens collected were transported, processed and stored according to the standard cold chain procedures as done by Waithaka et al. [1] 
Citation: Gitimu MR, Njangiru KI, Mutua ND, Waithaka KS, Juma KK, et al. (2016) Paediatric and Young Adults Reference Values for Renal, Cardiac and Pancreatic Function Tests for the Population of Taita Taveta County. Biochem Anal Biochem 5: 295. doi:10.4172/2161-1009.1000295

Page 3 of 6

\begin{tabular}{|c|c|c|c|c|c|c|c|c|c|}
\hline \multirow{2}{*}{ Analytes (Unit) } & \multirow{2}{*}{ Sex } & \multicolumn{8}{|c|}{ Reference range at varying age intervals } \\
\hline & & $1-5$ years & $\mathbf{N}$ & $6-10$ years & $\mathbf{N}$ & $11-15$ years & $\mathbf{N}$ & $>15$ years & $\mathbf{N}$ \\
\hline \multirow{2}{*}{ BUN (mmol/L) } & M & $4.00 \pm 1.18$ & 36 & $6.42 \pm 1.36^{*}$ & 74 & $4.27 \pm 1.79^{*}$ & 86 & $3.77 \pm 0.85$ & 81 \\
\hline & $\mathrm{F}$ & $3.70 \pm 0.98$ & 27 & $4.07 \pm 1.30$ & 75 & $4.10 \pm 2.18$ & 88 & $3.73 \pm 1.00$ & 72 \\
\hline \multirow{2}{*}{$\mathrm{UA}(\mu \mathrm{mol} / \mathrm{L})$} & M & $187.98 \pm 76.70$ & 17 & $200.49 \pm 76.00$ & 41 & $219.95 \pm 68.70$ & 58 & $216.32 \pm 68.20$ & 73 \\
\hline & $\mathrm{F}$ & $167.13 \pm 56.46$ & 19 & $170.2 \pm 40.02$ & 36 & $198.40 \pm 72.16$ & 47 & $216.77 \pm 55.50^{\mathrm{ce}}$ & 60 \\
\hline \multirow{2}{*}{ PHOS (mmol/L) } & M & $3.28 \pm 1.43$ & 19 & $2.14 \pm 0.97$ & 41 & $1.94 \pm 0.88^{\star}$ & 58 & $1.79 \pm 0.80$ & 73 \\
\hline & $\mathrm{F}$ & $3.29 \pm 1.68$ & 16 & $2.78 \pm 1.47$ & 36 & $2.55 \pm 1.25$ & 47 & $1.80 \pm 0.88^{\text {cef }}$ & 60 \\
\hline \multirow{2}{*}{$\mathrm{NA}(\mathrm{mmol} / \mathrm{L})$} & M & $145.95 \pm 4.45$ & 17 & $142.82 \pm 6.05$ & 37 & $142.15 \pm 6.91$ & 53 & $139.73 \pm 6.80^{c}$ & 53 \\
\hline & $\mathrm{F}$ & $144.01 \pm 1.46$ & 16 & $145.61 \pm 1.47$ & 35 & $143.61 \pm 0.90$ & 42 & $141.42 \pm 1.04$ & 35 \\
\hline \multirow{2}{*}{$\mathrm{K}(\mathrm{mmol} / \mathrm{L})$} & $M$ & $4.98 \pm 1.59$ & 33 & $4.84 \pm 1.71$ & 81 & $4.91 \pm 1.27^{b}$ & 81 & $4.62 \pm 0.82$ & 61 \\
\hline & $\mathrm{F}$ & $5.37 \pm 1.66$ & 26 & $4.63 \pm 1.23$ & 74 & $4.87 \pm 1.34$ & 82 & $4.55 \pm 0.64$ & 46 \\
\hline \multirow{2}{*}{$\mathrm{C}(\mathrm{mmol} / \mathrm{L})$} & M & $107.49 \pm 5.09$ & 17 & $105.96 \pm 4.59$ & 37 & $104.60 \pm 4.89$ & 53 & $103.30 \pm 8.21$ & 53 \\
\hline & $\mathrm{F}$ & $105.38 \pm 4.16$ & 16 & $105.61 \pm 6.10$ & 35 & $104.66 \pm 3.29$ & 42 & $104.32 \pm 7.14$ & 35 \\
\hline \multirow{2}{*}{$\mathrm{CA}(\mathrm{mmol} / \mathrm{L})$} & M & $2.36 \pm 0.38$ & 35 & $2.34 \pm 0.31$ & 75 & $2.43 \pm 0.36$ & 81 & $2.26 \pm 0.22$ & 61 \\
\hline & $\mathrm{F}$ & $2.20 \pm 0.33$ & 27 & $2.37 \pm 0.04$ & 75 & $2.35 \pm 0.27$ & 83 & $2.32 \pm 0.30$ & 46 \\
\hline \multirow{2}{*}{ CK (U/L) } & M & $190.03 \pm 95.50$ & 19 & $196.56 \pm 103.90^{*}$ & 41 & $185.84 \pm 79.80^{*}$ & 58 & $169.87 \pm 105.00$ & 73 \\
\hline & $\mathrm{F}$ & $169.54 \pm 98.03$ & 17 & $153.45 \pm 62.96$ & 36 & $147.91 \pm 64.92$ & 47 & $146.95 \pm 60.00$ & 60 \\
\hline \multirow{2}{*}{ AMYL (U/L) } & $M$ & $114.56 \pm 54.60$ & 36 & $102.16 \pm 34.40$ & 75 & $96.35 \pm 39.80$ & 86 & $89.50 \pm 33.50^{c}$ & 82 \\
\hline & $\mathrm{F}$ & $102.81 \pm 34.06$ & 27 & $108.17 \pm 38.86$ & 75 & $101.58 \pm 40.69$ & 88 & $93.23 \pm 29.25$ & 72 \\
\hline
\end{tabular}

Results are expressed as Mean \pm Standard deviation of the number of subjects indicated in the column labeled N. ${ }^{*} \mathrm{p} \leq 0.05$ when male reference ranges are compared to female reference ranges per each age category; a $\leq 0.05$ when reference ranges in age range $1-5$ years is compared to reference ranges in age range $6-10$ years; ${ }^{b} p \leq 0.05$ when reference ranges in age range $1-5$ years is compared to reference ranges in age range $11-15$ years; ${ }^{c} p \leq 0.05$ when reference ranges in age range $1-5$ years is compared to reference ranges in age range 6-15 years; ${ }^{d} p \leq 0.05$ when reference ranges in age range $1-5$ years is compared to reference ranges in age range $6-10$ years; ${ }^{d} p \leq 0.05$ when reference ranges in age range 6-10 years is compared to reference ranges in age range $11-15$ years; ${ }^{\mathrm{e}} \mathrm{p} \leq 0.05$ when reference ranges in age range 6-10 years is compared to reference ranges in age range $>15$ years; $f p \leq 0.05$ when reference ranges in age range $11-15$ years is compared reference ranges in to age range $>15$ years.

Table 2: Age and sex related reference ranges for BUN, UA, PHOS, NA, K, CL, CA, CK and AMYL for infants and children of Taita Taveta County, Kenya.

\section{Laboratory analysis}

Ten renal function tests done included: Uric acid (UA), creatine kinase (CK), urea (BUN), amylase (AMYL), creatinine (CREAT) and electrolytes were determined on the serum processed from blood samples. Standard procedures prepared by the Moi District Hospital, Voi were used for this study. All tests were done using Cobas Integra 400 plus automatic Chemistry Analyzer (Roche Diagnostics, Mannheim, Germany)

\section{Calibration of tests}

Calibrator for automated systems (C.f.a.s) was used. The system performed calibrations automatically.

\section{Quality assurance (QA)/Quality control (QC)}

To ensure accuracy and precision of the test results, all pre-analytical, analytical and post analytical precautions were taken into consideration. Internal QC materials (Precinorm and Precipath) were procured from Roche diagnostics and run according to the instructions of the manufacturer. Similarly, the American Proficiency Institute (API) external QC material was used for monitoring performance and participation at the Moi District Hospital Laboratory and run twice within the period of analysis. This was performed according to the instructions of the manufacturers and QC protocols. Quality control was done automatically as defined in the test specification for every analysis [4].

\section{Data management and statistical analysis}

The data was entered into a spread sheet and cleaned. Box plot was used for identification of outliers [5]. The data was then uploaded to SPSS v.20 for determination of the quartiles and interquartile range. Outliers were determined using the procedure adopted by Waithaka et al. [1]. A test of normality was also done [6]. Reference values and medians were calculated at $95 \%$ confidence interval. Comparison for variations between the genders was done using Mann Whitney test. Significant differences were determined at a value of $p \leq 0.05$. Comparison for different ages on the basis of gender was determined using One Way Anova followed by Dennett's test for multiple comparisons [7].

\section{Results}

\section{Establishment of reference ranges for infants and children of Taita Taveta County, Kenya}

All the renal function tests (RFTs) comprising Urea, creatinine, Potassium and Chloride were similar while sodium showed significant variation on the basis of sex $(p \leq 0.05)$. There was also variation on the basis of gender for uric acid while calcium and Phosphorous for both genders were similar. The enzyme Amylase showed no significant sex differences $(p>0.05)$ whilst Creatinine kinase showed significant sex difference $(\mathrm{p}>0.05)$ (Table 1). During the entire analytical period, everyday control value result and the standard deviation (SD) from the control target value were noted. All the daily QC runs were within \pm 2SD from the target values.

\section{Reference values for healthy infants and children in different age groups for Taita Taveta County, Kenya}

In children aged between 6-10 years, male children had significantly higher levels of Urea (BUN) and Creatinine kinase than their female counter parts. In children aged between 11-15 years, male children had significantly lower levels of Phosphorous, and significantly higher levels of Urea, and Creatinine kinase than their female counter parts. Male infants and children had: a significantly decreased level of Potassium, Amylase, and Sodium in children aged more than 15 years compared to children aged between 1-5 years old (Table 2).

Female infants and children had: a significantly decreased level of Phosphorous and a significantly increased level of uric acid in children 
Citation: Gitimu MR, Njangiru KI, Mutua ND, Waithaka KS, Juma KK, et al. (2016) Paediatric and Young Adults Reference Values for Renal, Cardiac and Pancreatic Function Tests for the Population of Taita Taveta County. Biochem Anal Biochem 5: 295. doi:10.4172/2161-1009.1000295

Page 4 of 6

\begin{tabular}{|c|c|c|c|c|c|c|c|c|c|}
\hline & \multirow{2}{*}{ Sex } & \multicolumn{8}{|c|}{ Mean ( Reference Ranges) } \\
\hline & & $1-5$ years & $\mathbf{N}$ & $6-10$ years & $\mathbf{N}$ & $11-15$ years & $\mathbf{N}$ & $>15$ years & $\mathbf{N}$ \\
\hline \multirow[t]{2}{*}{$\mathrm{K}(\mathrm{mmol} / \mathrm{L})$} & M & $3.39-6.57$ & 33 & $3.13-6.55$ & 81 & $3.64-6.18$ & 81 & $3.8-5.44$ & 61 \\
\hline & $\mathrm{F}$ & $3.71-7.03$ & 26 & $3.4-5.86$ & 74 & $3.53-6.21$ & 82 & $3.91-5.19$ & 46 \\
\hline \multirow{2}{*}{$\begin{array}{c}\mathrm{CA} \\
(\mathrm{mmol} / \mathrm{L})\end{array}$} & M & $1.98-2.72$ & 35 & $2.3-2.65$ & 75 & $2.07-2.79$ & 81 & $2.04-2.48$ & 61 \\
\hline & $\mathrm{F}$ & $1.87-2.53$ & 27 & $2.37-2.41$ & 75 & $2.08-2.62$ & 83 & $2-2.6$ & 46 \\
\hline AMYL & M & $59.96-169.16$ & 36 & $67.76-136.56$ & 75 & $56.55-136.15$ & 86 & $56-123$ & 82 \\
\hline$(\mathrm{U} / \mathrm{L})$ & $\mathrm{F}$ & $68.75-136.87$ & 27 & $69.31-147.03$ & 75 & $60.89-142.27$ & 88 & $63.98-122.48$ & 72 \\
\hline
\end{tabular}

Results are expressed as Mean \pm Standard deviation of the number of subjects indicated in the column labeled $\mathrm{N}$. ${ }^{*} \mathrm{p}<0.05$ when male reference ranges are compared to female reference ranges per each age category; ${ }^{a} p<0.05$ when reference ranges in age range $1-5$ years is compared to reference ranges in age range $6-10$ years; ${ }^{b} p<0.05$ when reference ranges in age range 1-5 years is compared to reference ranges in age range 11-15 years; ${ }^{c} p<0.05$ when reference ranges in age range $1-5$ years is compared to reference ranges in age range 6-15 years; ${ }^{d} p<0.05$ when reference ranges in age range 1-5 years is compared to reference ranges in age range $6-10$ years; ${ }^{d} p<0.05$ when reference ranges in age range $6-10$ years is compared to reference ranges in age range $11-15$ years; ${ }^{e} p<0.05$ when reference ranges in age range $6-10$ years is compared to reference ranges in age range $>15$ years; ${ }^{f} p<0.05$ when reference ranges in age range $11-15$ years is compared reference ranges in to age range $>15$ years.

Table 3: Reference values for electrolyte and enzymes as per age and sex for 1-17 years of Taita Taveta County, Kenya.

\begin{tabular}{|c|c|c|c|c|c|c|c|c|c|}
\hline \multirow{4}{*}{$\begin{array}{c}\text { Analyte (units) } \\
\begin{array}{c}\text { Urea } \\
(\mathrm{mmol} / \mathrm{L})\end{array}\end{array}$} & \multirow{3}{*}{$\begin{array}{c}\text { Sex } \\
M\end{array}$} & \multicolumn{8}{|c|}{ Mean (Reference Ranges) } \\
\hline & & $1-5$ years & $\mathbf{N}$ & $6-10$ years & $\mathbf{N}$ & $11-15$ years & $\mathbf{N}$ & $>15$ years & $\mathbf{N}$ \\
\hline & & $2.82-5.18$ & 36 & $5.06-7.78$ & 74 & $2.48-6.06$ & 86 & $2.92-4.62$ & 81 \\
\hline & $\mathrm{F}$ & $2.72-4.68$ & 27 & $2.77-5.37$ & 75 & $1.92-6.28$ & 88 & $2.73-4.73$ & 72 \\
\hline \multirow{2}{*}{$\begin{array}{c}\mathrm{NA} \\
(\mathrm{mmol} / \mathrm{L})\end{array}$} & M & $141.5-150.4$ & 17 & $136.77-148.87$ & 37 & $135.24-149.06$ & 53 & $132.93-146.53$ & 53 \\
\hline & $\mathrm{F}$ & $142.55-145.47$ & 16 & $144.14-147.08$ & 35 & $143.01-144.21$ & 42 & $140.38-142.46$ & 35 \\
\hline \multirow{2}{*}{$\begin{array}{c}\mathrm{CL} \\
(\mathrm{mmol} / \mathrm{L})\end{array}$} & M & $102.4-112.58$ & 17 & 101.37-110.55 & 37 & $99.71-109.49$ & 53 & $95.09-11.51$ & 53 \\
\hline & $\mathrm{F}$ & $101.22-109.54$ & 16 & $99.51-111.71$ & 35 & $101.37-107.95$ & 42 & $97.18-111.46$ & 35 \\
\hline \multirow{2}{*}{$\begin{array}{l}\text { PHOS } \\
(\mathrm{mmol} / \mathrm{L})\end{array}$} & $M$ & $1.85-4.71$ & 19 & $1.17-3.11$ & 41 & $1.06-2.82$ & 58 & $0.99-2.59$ & 73 \\
\hline & $\mathrm{F}$ & $1.61-4.97$ & 16 & $1.31-4.25$ & 36 & $1.3-3.8$ & 47 & $0.92-2.68$ & 60 \\
\hline \multirow{2}{*}{$\begin{array}{c}\text { CK } \\
(\mathrm{U} / \mathrm{L})\end{array}$} & M & $94.53-285.53$ & 19 & $92.66-300.46$ & 41 & $106.04-265.64$ & 58 & $64.87-274.87$ & 73 \\
\hline & $\mathrm{F}$ & $71.51-267.57$ & 17 & $90.49-216.41$ & 36 & $82.99-212.83$ & 47 & $86.95-206.95$ & 60 \\
\hline \multirow{2}{*}{$\begin{array}{c}\mathrm{UA} \\
(\mu \mathrm{mol} / \mathrm{l})\end{array}$} & M & $111.28-264.68$ & 17 & $124.49-276.49$ & 41 & $151.25-288.65$ & 58 & $148.12-284.52$ & 73 \\
\hline & $\mathrm{F}$ & $110.67-223.59$ & 19 & $130.18-210.22$ & 36 & $126.24-270.56$ & 47 & $161.27-272.27$ & 60 \\
\hline \multirow{2}{*}{$\begin{array}{c}\text { CREAT } \\
(\mathrm{U} / \mathrm{L})\end{array}$} & M & $61.14-73.86$ & 2 & 41.21-95.09 & 2 & $51.7-81.18$ & 26 & $51.78-75.98$ & 69 \\
\hline & $\mathrm{F}$ & - & - & - & & $53.44-75.22$ & 6 & $56.78-78.56$ & 50 \\
\hline
\end{tabular}

Results are expressed as Mean \pm Standard deviation of the number of subjects indicated in the column labelled $\mathrm{N}$. ${ }^{*} \mathrm{p}<0.05$ when male reference ranges are compared to female reference ranges per each age category; ${ }^{a} p<0.05$ when reference ranges in age range $1-5$ years is compared to reference ranges in age range $6-10$ years; ${ }^{b} p<0.05$ when reference ranges in age range 1-5 years is compared to reference ranges in age range $11-15$ years; ${ }^{c} p<0.05$ when reference ranges in age range $1-5$ years is compared to reference ranges in age range $6-15$ years; ${ }^{d} p<0.05$ when reference ranges in age range $1-5$ years is compared to reference ranges in age range $6-10$ years; ${ }^{\mathrm{d}} \mathrm{p}<0.05$ when reference ranges in age range $6-10$ years is compared to reference ranges in age range $11-15$ years; ${ }^{\mathrm{e}} \mathrm{p}<0.05$ when reference ranges in age range $6-10$ years is compared to reference ranges in age range $>15$ years; ${ }^{f} p<0.05$ when reference ranges in age range $11-15$ years is compared reference ranges in to age range $>15$ years.

Table 4: Reference values for renal, electrolyte and enzymes (BUN, NA, CL, CK, UA and CREAT) as per age and sex for 1-17 years of Taita Taveta County, Kenya.

aged more than 15 years compared to children aged 1-5 years old; a significantly decreased level of Phosphorous in children aged more than 15 years compared to children aged between $6-10$ years ; a significantly decreased level of Phosphorous and a significantly increased level of Uric acid in children aged more than 15 years compared to children aged between 11-15 years (Table 2). The biochemical parameters: Calcium, Chloride, Creatinine Kinase and Urea are not affected by the age of infants and children (Table 2).

The results for significance difference in females for Uric acid between the four groups, 1-5 years, 6-10 years, 11-15 years and over 16 years (Table 3 ) while there was no significance in different age groups in Potassium, Calcium, Amylase, Urea, Sodium, Chloride and Creatine Kinaseat $\mathrm{p}<0.05$. For the Phosphorous, Potassium, Calcium, Amylase, Urea, Sodium, Chloride, Uric acid, Creatinine Kinase and Creatinine showed no significance difference between age groups for the male population of ages $1-17$ years at $p<0.05$. In there was no significance differences in both male and female of all age groups for all the analytes Potassium, Calcium, Amylase, Urea, Sodium, Chloride, GGT, Uric Acid, Creatinine Kinase, and Creatinine at $\mathrm{p}<0.05$ (Table 4).
Male and females of age 6-10 showed significance deference in their references ranges for, Uric acid and Creatinine Kinase while Kinase, Calcium, Amylase, Urea, Sodium, Chloride, and Creatinine at $\mathrm{p}<0.05$ (Tables 3 and 4). Significance difference was shown in Urea, Potassium and Creatine kinase for ages 11-15 years for both male and females, while no significance was noted in Potassium, Calcium,Amylase, Sodium, Chloride, Uric acid, and Creatinine (Tables 3 and 4$)$ at $\mathrm{p}<0.05$. For ages above 16 years at $\mathrm{P}<0.05$, there was no significance was noted in Potassium, Calcium, AmylaseL, Sodium, Chloride, Urea, Creatinine Kinase, Uric acid and Creatinine. For comparison with references in literature, there was no established significant differences found in the same age bracket (1-5 years, 6-10 years, 11-15 years and 16-17 years) as those in the study. During the entire study period, everyday control value result and the standard deviation (SD) from the control target value were noted. All the daily QC runs were within \pm 2 SD from the target values (Figures 1-8).

\section{Discussion}

This study provides the first established clinical chemistry reference 
Citation: Gitimu MR, Njangiru KI, Mutua ND, Waithaka KS, Juma KK, et al. (2016) Paediatric and Young Adults Reference Values for Renal, Cardiac and Pancreatic Function Tests for the Population of Taita Taveta County. Biochem Anal Biochem 5: 295. doi:10.4172/2161-1009.1000295

Page 5 of 6

values for children aged 1-17 years for both males and females in Taita Taveta County, Kenya derived from healthy individuals. Out of 577 participants recruited, only 553 were involved in the study. The number of males (276) was almost equal to that of females (277), each group exceeded the minimum of 120 participants per subgroup for nonparametric estimates required for $95 \%$ reference interval determination as recommended by CLSI [7]. Both the internal and external controls were used for quality control of the study besides using procedures set at the facility [4].

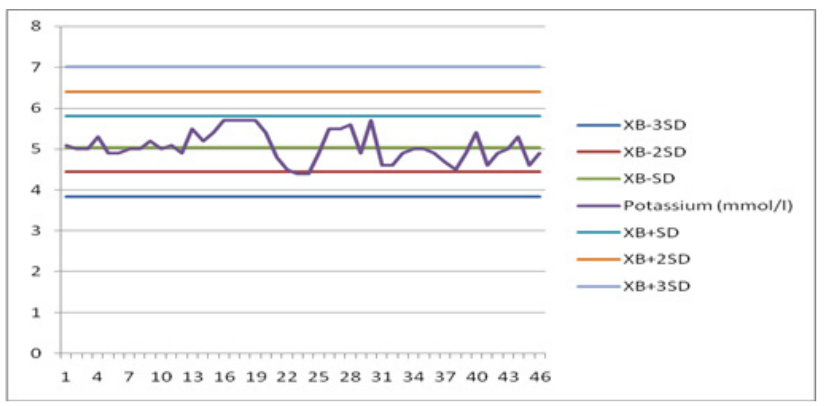

Figure 1: Levy-Jennings control chart for potassium (normal).

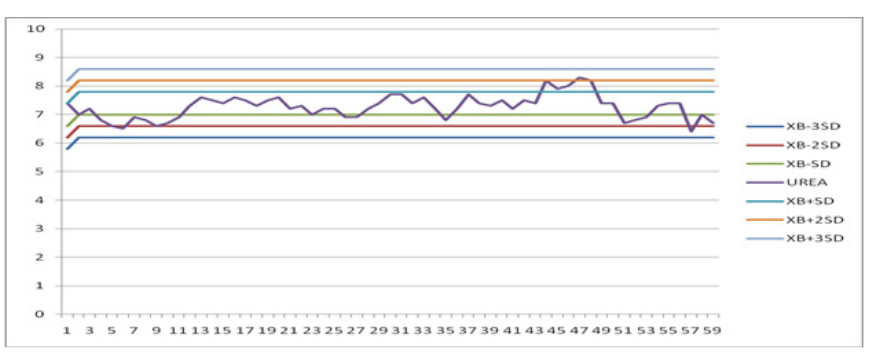

Figure 2: Levy-Jennings control chart for urea (normal).

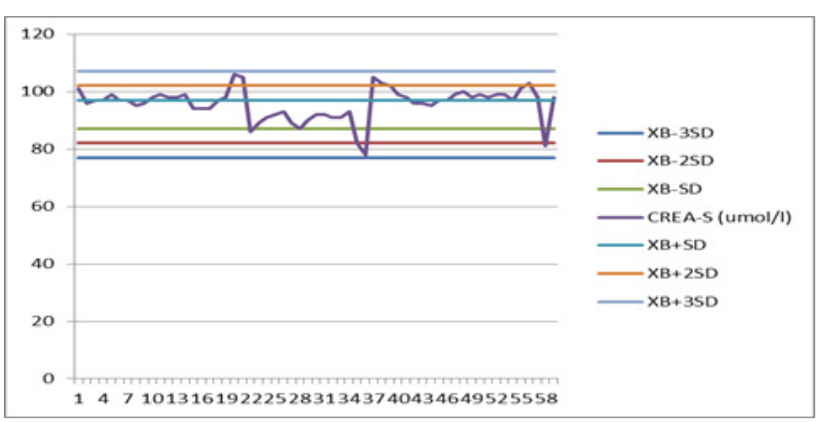

Figure 3: Levy-Jennings control chart for crea-s (normal).

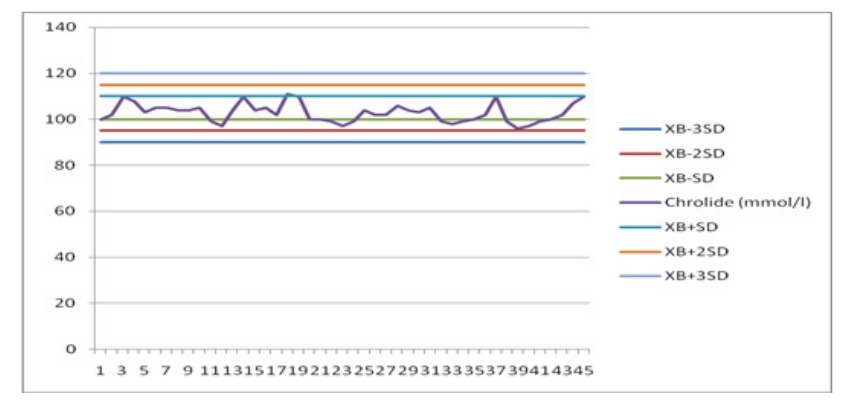

Figure 4: Levy-Jennings control chart for chloride (normal).

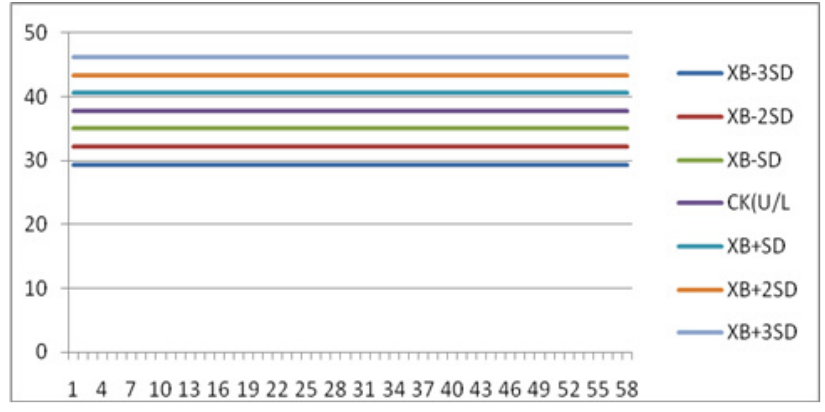

Figure 5: Levy-Jennings control chart for CK (normal).

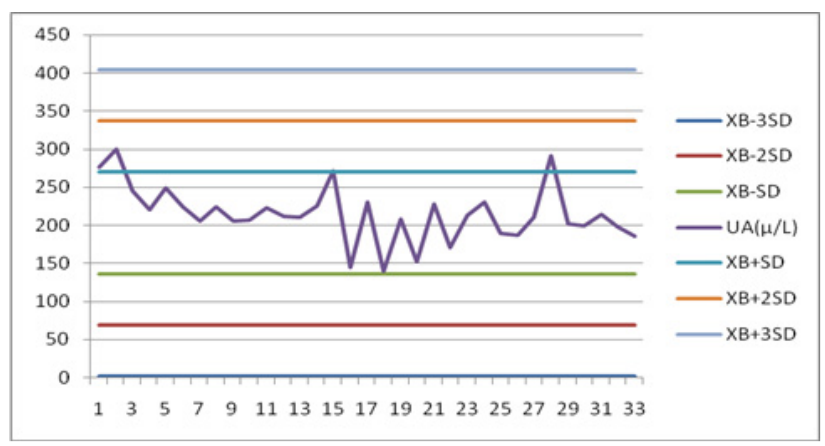

Figure 6: Levy-Jennings control chart for UA (normal).

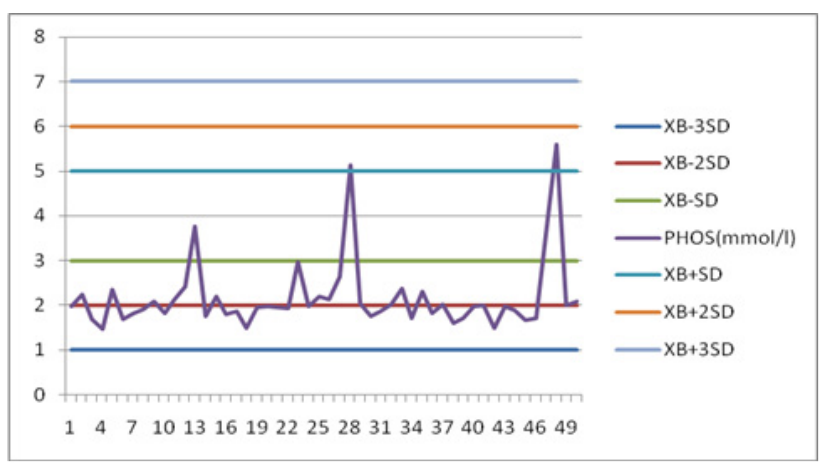

Figure 7: Levy-Jennings control chart for PHOS (normal).

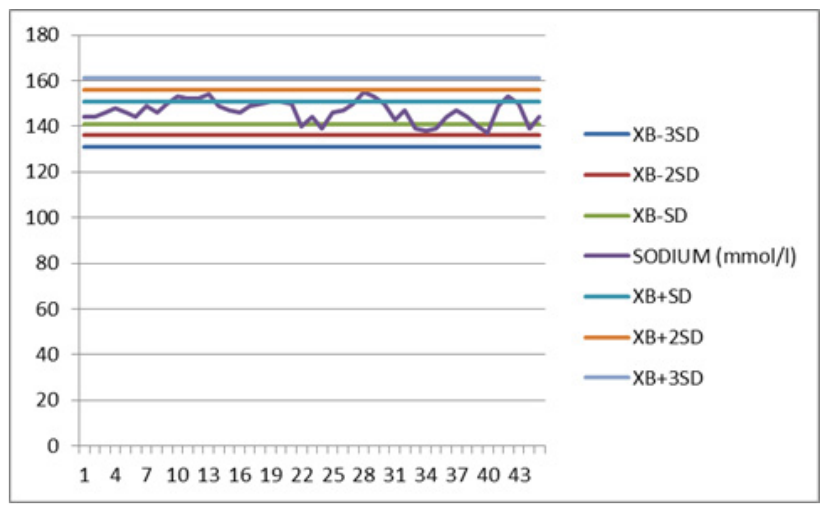

Figure 8: Levy-Jennings control chart for sodium (normal).

There was significant variation in values for Creatinine kinase, and Sodium in male compared to female children. This suggests differences 
Citation: Gitimu MR, Njangiru KI, Mutua ND, Waithaka KS, Juma KK, et al. (2016) Paediatric and Young Adults Reference Values for Renal, Cardiac and Pancreatic Function Tests for the Population of Taita Taveta County. Biochem Anal Biochem 5: 295. doi:10.4172/2161-1009.1000295

Page 6 of 6

in these values for different genders for these parameters. Other studies report similar findings for adult black populations in east Africa, and USA [8-12]. It is shown that males have higher values for Creatinine kinase compared to females contributed by a higher mass of muscles and bone mass $[13,14]$. As a child grows, the muscle mass increases but mechanical shock to muscle decreases and therefore explaining the decrease in Creatinine Kinase as the children grow from 1-17 years due to reduction in activity.

The variations in values for Sodium and Uric acid in the different sexes may be associated with the different responses to dietary salts. This may be explained by the variations in the sex hormone and genetic factors which vary in the different sexes. Other similar findings in adult populations have been determined in Rwanda [9]. Variation in uric acid have also been done $[8,10,11]$. This is suggested to be as a result of differences in sex hormones and body mass. The observed variations in the biochemical analytes in different ages and sexes may be an indication that some of the parameters are age dependent. The increase in serum reference range for Uric acid in males with progression of age could be as a result of the increase in weight with advancing age as suggested by Kuzuya et al. [15]. The decrease in serum reference range for Amylase in females with progression of age could be partly due to a decrease in pancreatic function and integrity with age and genetics; This is in agreement with other study findings [16]. The significance increase in Phosphorous in early stages in children life is attributed to bone growth, but this reduces as they approach adulthood as the bone growth has reduced. This can also be affected by diet. Low vitamin $\mathrm{D}$ and high calcium have some effect on Phosphorous.

Both kidney evaluation parameters vary with those in manufactures reference ranges [8], this could be attributed to the fact that the organs are not fully developed. Amylase was extremely high that manufacturer's reference ranges [8] but as they approach the age of 17 years they concur with manufacturer's ranges. From the research it was noted that there was variation in as per age, sex in all categories, this could be contributed to diet, environmental factors [17] and analytical methods as indicated by Eller et al. [10].

Different lifestyles and genetic composition of different populations could also explain the differences among the different genders and within the same genders as females and males as shown in Tables 3 and 4 respectively. These differences have also been reported from other countries $[10,11,18]$.

Generally, physiological functions have been shown to vary with population due to differences in diet, genetics, physical, environmental and socio-economic conditions $[19,20]$.

The reference values for most analytes determined in this study vary from the same population. This indicates that there is need to determine gender and age established values which will be applicable to specific populations for different geographical regions, with different diets and minerals salts present in the soils rather than using reference values determined for all population from different geographical regions and applied for all people [20].

\section{Conclusion}

The study has enabled the renal, cardiac and pancreatic reference ranges for Taita Taveta, Kenya, which is independently from those that are quoted by reagent's manufacturers in addition to those quoted in medical books. There was evidence that some of the parameters vary with those in literature. This has been supported by similar studies done in other counties and with different population all over the world.

\section{Acknowledgement}

The authors would like to thank all those who willingly participated in the study, staff of Moi District County hospital and Taita Taveta University college health staff for their technical assistance.

\section{References}

1. Waithaka S, Njagi E, Ngeranwa J, Kigondu C (2009) Reference ranges of some biochemical parameters for adults of Kenyan population. International Journal of Healthy Research 2: 257-269.

2. Harris EK, Cooil BK, Shakarji G, Williams GZ (1980) On the use of statistical models of within person variation in long-term studies of healthy individuals. Clinical Chemistry Journal 26: 383-391.

3. Villanova PA (2000) How to define determine and utilize reference intervals in the Clinical Laboratory. Approved guideline NCCLS Publications.

4. Ohmann S (1997) Quality control for clinical chemistry laboratory. Quality Assurance 5: 79-93.

5. Horn PS, Pesce AJ (2003) Reference intervals: An update. Clin Chim Acta 334: 5-23.

6. CLIA'88 (1988) Federal Register 57, February 28.

7. Roche Cobras Integra 400 plus (2008) Method Manual ver. 3.0 Roche diagnostics, Germany

8. Gahutu JB, Wane J (2006) Reference intervals for serum proteins and electrolytes from student population in Butare Rwanda. East Afr Med J 83 64-67.

9. Saathoff E, Schneider P, Kleinfeldt V, Geis S, Haule D, et al. (2008) Laboratory reference values for healthy adults from Southern Tanzania. Trop Med Int Health. 13: 612-625

10. Eller LA, Eller MA, Ouma B, Kataaha P, Kyabaggu D, et al. (2008) Reference intervals in healthy adult Ugandan blood donors and their impact on conducting international vaccine trials. PLOS ONE 3:1-6.

11. Kibaya RS, Bautista CT, Sawe FK, Shaffer DN, Sateren WB, et al. (2008) Reference ranges for the clinical laboratory derived from a rural population in Kericho Kenya. PLoS ONE 3: 1-7.

12. Chan AOK, Lee KC, Leung JS, Shek CC (2008) Reference intervals of common serum analytes of Hong Kong Chinese. J Clin Pathol 61: 632-636

13. Ichihara I, Itoh Y, Lam CWK, Poon PMK, Kim J, et al. (2008) Sources of variation of commonly measured serum analytes. Clin Chem 54: 356-365.

14. Kuzuya M, Ando F, Iguchi A, Shimokata H (2002) Effect of aging on serum uric acid levels: Longitudinal changes in a large Japanese population group. Journal of Gerontology 57: 660-664.

15. Bossuyt PM, Schuurman PR, Bosch DA, Bonsel GJ, Van Someren EJ (1981) Establishment of age-specific reference values nutrition and immune function. Surgery Annual 13: 15-29.

16. Manialo TA, Burke GL, Savage PJ, Jacobs DR, Sidney S, et al. (1992) Sex and race related differences in liver associated serum chemistry tests in young adults in the CARDIA study. Clin Chem 38: 1853-1859.

17. Olusi SO, Al-Awadhi AM (2002) Age and sex related reference intervals for blood chemistry analytes in Kuwaitis aged 15 years and older. Kuwait Medical Journal 34 : 114-127.

18. Koram KA, Addae MM, Ocran JC, Adu-Amankwah S, Rogers WO et al. (2007) Population based reference intervals for common blood haematological and biochemical parameters in the Akuapem North district. Ghana Med J 41: 160-166.

19. IFCC (1987) Approved recommendation on the theory of reference values Journal of Clinical Chemistry and Clinical Biochemistry 25: 337-342.

20. Khan F, Dilawar M, Khan D (1997) Reference values of common blood chemistry analytes in healthy population of Rawalpindi-Islamabad area. Journal of Pakistan Medical Association 47: 156-159. 